\title{
Heparin-Eluting Tissue-Engineered Bioabsorbable Vascular Grafts
}

\author{
Yuichi Matsuzaki ${ }^{1,+}$, Anudari Ulziibayar ${ }^{1,+}$, Toshihiro Shoji ${ }^{1}$ and Toshiharu Shinoka $1,2, *$ (D) \\ 1 Center for Regenerative Medicine, The Abigail Wexner Research Institute, Nationwide Children's Hospital, \\ Columbus, OH 43205, USA; Yuichi.Masuzaki@nationwidechildrens.org (Y.M.); \\ Anudari.Ulziibayar@nationwidechildres.org (A.U.); Toshihiro.Shoji@nationwidechildrens.org (T.S.) \\ 2 The Heart Center, Department of Cardiothoracic Surgery, Nationwide Children's Hospital, \\ Columbus, OH 43205, USA \\ * Correspondence: toshiharu.shinoka@nationwidechildrens.org; Tel.: +1-614-722-3103; Fax: +1-614-722-3111 \\ + Co-first author.
}

Citation: Matsuzaki, Y.; Ulziibayar, A.; Shoji, T.; Shinoka, T. Heparin-Eluting Tissue-Engineered Bioabsorbable Vascular Grafts. Appl. Sci. 2021, 11, 4563. https://doi.org/ 10.3390/app11104563

Academic Editor: Joen-Rong Sheu

Received: 17 March 2021

Accepted: 5 May 2021

Published: 17 May 2021

Publisher's Note: MDPI stays neutral with regard to jurisdictional claims in published maps and institutional affiliations.

Copyright: (c) 2021 by the authors. Licensee MDPI, Basel, Switzerland. This article is an open access article distributed under the terms and conditions of the Creative Commons Attribution (CC BY) license (https:// creativecommons.org/licenses/by/ $4.0 /)$.

\begin{abstract}
The creation of small-diameter tissue-engineered vascular grafts using biodegradable materials has the potential to change the quality of cardiovascular surgery in the future. The implantation of these tissue-engineered arterial grafts has yet to reach clinical application. One of the reasons for this is thrombus occlusion of the graft in the acute phase. In this paper, we first describe the causes of accelerated thrombus formation and discuss the drugs that are thought to inhibit thrombus formation. We then review the latest research on methods to locally bind the anticoagulant heparin to biodegradable materials and methods to extend the duration of sustained heparin release. We also discuss the results of studies using large animal models and the challenges that need to be overcome for future clinical applications.
\end{abstract}

Keywords: tissue-engineered vascular grafts; biodegradable material; anticoagulation; medication; heparin; large-animal study

\section{Introduction}

More than 550,000 surgical bypass procedures are performed annually in the United States for coronary artery disease and peripheral artery disease (PAD) [1]. However, an estimated 80,000 patients are unable to undergo life-saving or limb-saving bypass graft surgery due to the inadequate availability of autologous vascular graft material [2]. In addition, vessel harvesting increases operation times and patient complications, leading to graft fragility and increased risk of repeat surgery. Although these risks have been addressed by prosthetic grafts, existing non-bioabsorbable options only work well in large caliber vessels and are a significant source of morbidity and mortality from graft-related complications such as infection, occlusion, and calcification [3-5]. For these reasons, the development of small-diameter synthetic bioabsorbable grafts has been pursued as a viable alternative solution.

\section{Considerations}

Several key challenges need to be overcome for small-diameter bioabsorbable grafts to be successful. The first one is to resist thrombosis, while the second is to avoid intimal hyperplasia. Before we dive more into these challenges, we will delve into the factors that constitute scaffold fabrication. Afterwards, we will talk about how scaffolds relate to these challenges. With respect to bioabsorbable grafts, electrospinning has been the most prevalent means of fabricating a scaffold. This is because of electrospinning technologies' ability to create fibers at a nanometer scale, which mimics a natural extracellular matrix (ECM) [6-8]. An important point is that by controlling fiber size, scaffold porosity can also be changed. It is crucial to understand that increasing graft porosity encourages cellular 
migration, adhesion, and remodeling onto the scaffold. However, increasing graft porosity comes at the cost of losing mechanical properties and strength of the original scaffold [9].

Additionally, electrospinning is popular because of its ability to incorporate drugs, growth factors, and helpful peptides into the scaffold [10]. These helpful graft modifiers are often co-spun with various polymers during the scaffold fabrication process. Much has been written about the polymers used in bioabsorbable grafts and their various fabrication methods, so we will not go over them in much detail. The materials most often used are PGA, PLA, and PCL [11]. Using these polymers individually, or as blends, can create a wide range of mechanical properties and degradation periods. Additionally, these polymers are the widely used because they have been approved by the FDA for numerous medical applications, thereby making new device regulatory approval much simpler [12].

This brings us to our first challenge, that these graft materials have been susceptible to thrombosis. Thrombosis is largely due to the surface charge of a given graft polymer, which has little interaction with serum and allows for platelet deposition [13]. In general, graft polymers are positively charged materials, whereas albumin, the most abundant blood protein, and fibrinogen, a protein important for platelet-mediated blood clotting, both have negative charges at blood $\mathrm{pH}$ [14]. This is a major problem, because when the opposite charges of the material proteins attract, a coagulation cascade begins that often leads to thrombosis [15].

Thankfully, material surface charge can be manipulated by chemical and/or cellular modification. Although there are many approaches for chemical surface modification, the binding of heparin continues to be the most widely used and promising method to prevent thrombosis. The reason for this is that heparin has the highest negative charge density and electrostatically repels a variety of blood proteins of similar charge. Conjugating heparin to polymers effectively changes a scaffold's surface from positive to negative. Static repulsion, between heparin and these proteins, prevents albumin and fibrinogen from adhering to the graft [16].

The second major hurdle is a graft's ability to resist intimal hyperplasia (smooth muscle cell (SMC) overgrowth) $[17,18]$. Heparin has so far been the best candidate in the search for an anticoagulant to inhibit a graft's SMC proliferative response while promoting endothelial cell (EC) proliferation [19]. In fact, in vitro studies have shown that it inhibits SMC, but enhances EC proliferation. However, in vivo studies have been inconsistent. Heparin can be used directly as a coating inside of the graft (physical conjugation) or indirectly via additional linkers or spacers (chemical/plasma conjugation). However, it is not enough for heparin to be properly bound to the graft surface; it must be released in a controlled manner at sufficient concentrations [20,21].

Unfortunately, heparin release profiles in bioabsorbable grafts are often characterized by a large initial release of heparin, which we term as the initial burst. Often, very little to no heparin remains on the scaffold after this initial burst. Therefore, investigators are looking for ways to slow and control heparin release, which we term as heparin immobilization. The success of the bioabsorbable material relies on the controlled release of heparin. Satisfying the delicate balance between the time scale and the amount of heparin released is a key factor for the success of bioabsorbable grafts.

\section{Heparin Conjugation Methods}

\subsection{Physical Conjugation}

Physical conjugation is generally the most inexpensive way to apply heparin to bioabsorbable grafts. The three primary methods to physically conjugate heparin are: (1) gas plasma; (2) straight mixing with sulfated biopolymers; and (3) coaxial electrospinning (Table 1).

\subsubsection{Gas Plasma Methods}

There are several ways to anchor plasma-assisted heparin molecules to the scaffold through the formation of desirable surface functionalities (e.g., $-\mathrm{COOH}$ and $-\mathrm{NH}_{2}$ surface 
groups). The most common way to attach- $\mathrm{NH}_{2}$ surface groups to biopolymers is $\mathrm{NH}_{3}$ plasma treatment [22]. Although plasma polymerization is an effective way to coat various substrates with thin films, many coating precursors are usually highly toxic or cannot be directly incorporated into standard plasma processing equipment.

Cheng et al. investigated a much less toxic gas plasma method, capable of imparting appropriate surface functionalities to biopolymer surfaces for biomolecule immobilization, and which could be easily applied to most plasma treatment devices [23]. Specifically, the surface of electrospun fibrous scaffolds made of poly(lactic acid) (PLLA) was functionalized with $-\mathrm{NH}_{2}$ groups using a two-step plasma treatment process: (1) argon and $\mathrm{NH}_{3}$ mixed gas plasma treatment, and (2) $\mathrm{H}_{2}$ plasma treatment, to increase the density of surfaceconjugated sites for heparin immobilization. Their heparin-bound PLLA scaffolds were evaluated by X-ray photoelectron spectroscopy (XPS), heparin binding measurements, and platelet adhesion quantification. The results showed the potential of this plasma process, but this method has not been validated in vivo [Table 1]. 
Table 1. Bioabsorbable synthetic arterial graft-heparin conjugation methods.

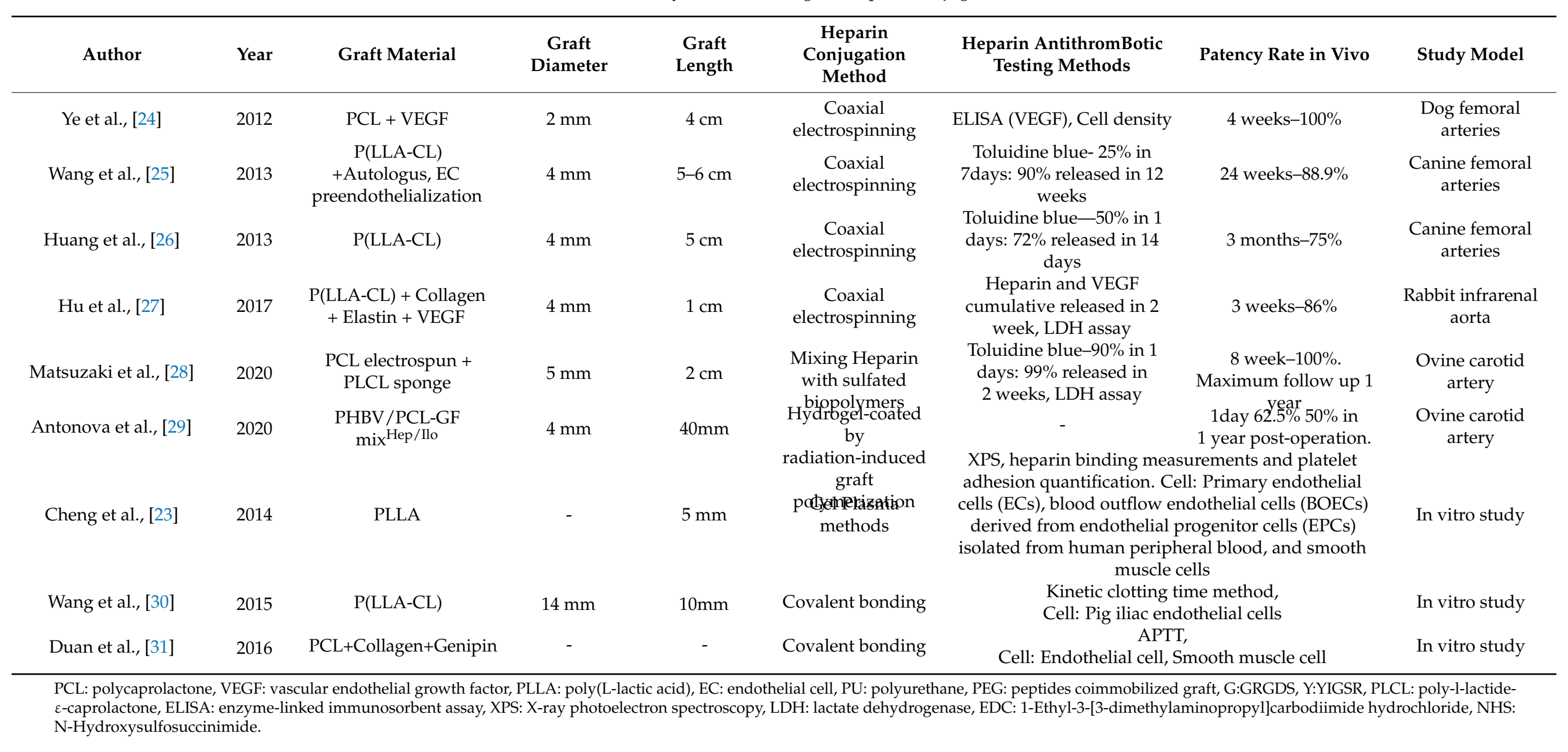




\subsubsection{Mixing Heparin with Sulfated Biopolymers}

Conjugating heparin through gas plasma results in lower heparin bioactivity, drug instability in high-pressured blood flow, and tissue toxicity [32]. The advantage of this conjugation technique is that it can be adopted quickly and is inexpensive compared to other methods. However, it has the disadvantage that heparin does not adhere to the graft polymer strongly and/or uniformly, so the initial burst when exposed to blood is unavoidable.

Matsuzaki et al., investigated dual-layered grafts made of an outer electrospun PCL layer and inner PLCL sponge layer with heparin [28]. Heparin was dissolved and separated by thermally induced phase separation (TIPS) to make a wet porous PLCL inner sponge (Figure 1). In order to evaluate the amount of heparin conjugated to the graft and how it affects platelet deposition, they activated sheep platelets in vitro and compared the extent to which they deposited on the graft in the heparin group and control group. A comparison was made using direct observation of the lumen by SEM and LDH assay methods for quantitative evaluation [33]. The results showed that platelet absorption was significantly suppressed in the heparin group. Heparin did not inhibit platelet aggregation; therefore, we considered that heparin may have changed the charge on the luminal surface.

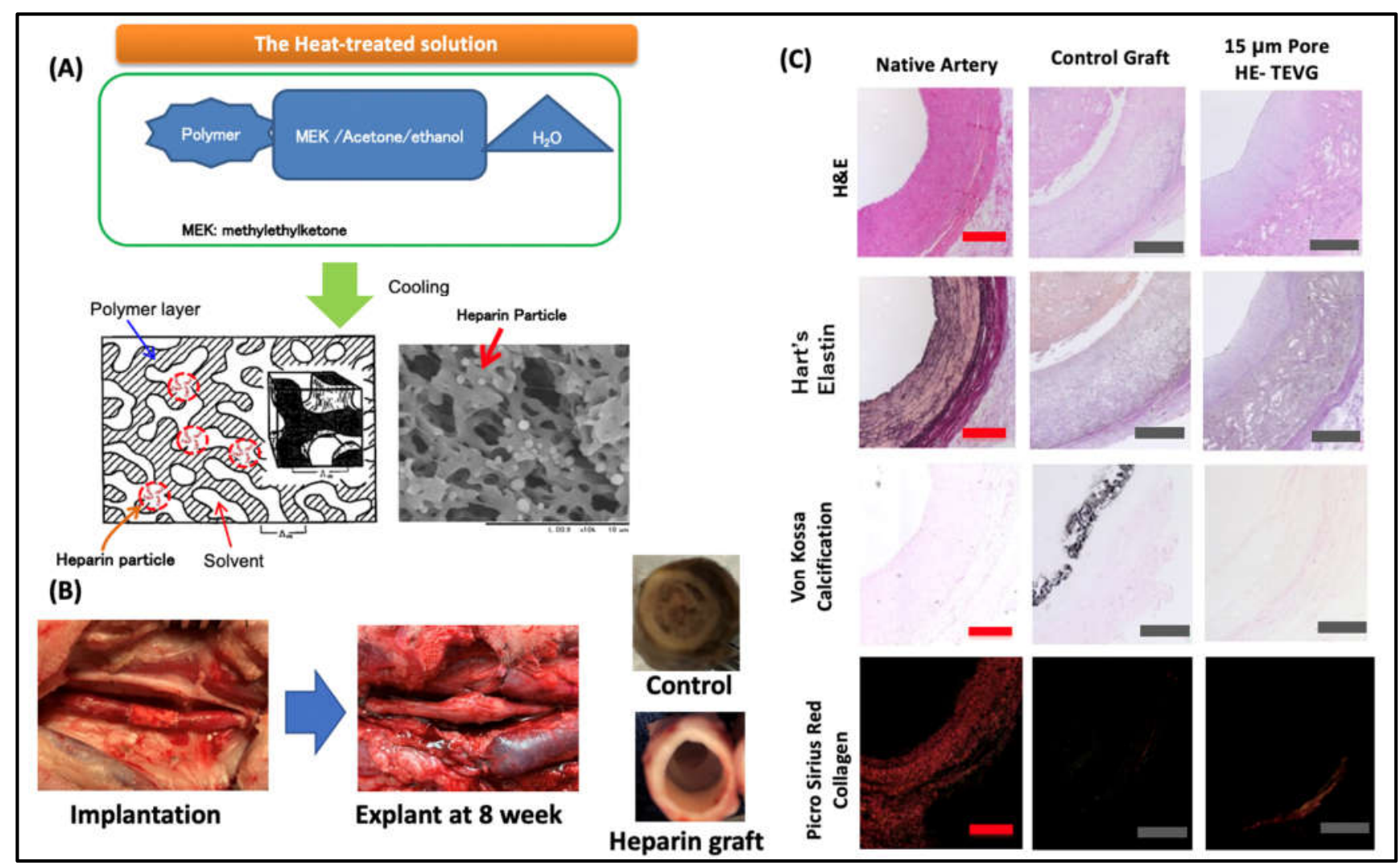

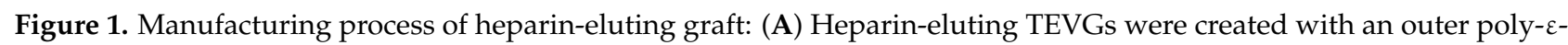
caprolactone (PCL) electrospun nanofiber layer with a $15 \mu \mathrm{m}$ average pore Scheme 50. poly(l-lactide-co- $\varepsilon$-caprolactone) copolymer (PLCL). SEM showed the inner heparin eluting layer; (B) Surgical implantation of TEVG to sheep carotid artery, 3 out of 5 Control grafts were occluded within 1 week. On the other hand, heparin-eluting grafts were obvious throughout the observation period; (C) Histological analysis of $15 \mu \mathrm{m}$ TEVG and occluded control TEVG, red bar $=200$ $\mu \mathrm{m}$, grey bar $=500 \mu \mathrm{m}$. HE, heparin-eluting; TEVG, tissue-engineered vascular graft. Adopted with permission from Shinoka et al.

They quantitatively examined the release of heparin using the toluidine blue method $[34,35]$. A large initial burst of heparin release occurred within $24 \mathrm{~h}$. However, continuous, albeit low, heparin release was observed for the next 14 days. They implanted this heparin graft 
in sheep carotid arteries and maintained patency for up to one year. The positives of this method are that it is simple and cost-effective.

Liu et al., fabricated a tissue-engineered small intestine, using a subcritical $\mathrm{CO}_{2}$ exposure system to slowly release heparin-binding EGF-like growth factor (HBF-GF) embedded in a PGA/PLLA scaffold. Heparin-binding EGF-like factor (HBF-GF) embedded in PGA/PLLA scaffolds was successfully released slowly in an active form [36] and was able to stimulate crypt growth in vitro and intestinal mucosa formation in vivo. A notable aspect of this technique is that exposure to subcritical $\mathrm{CO}_{2}$ does not deform the scaffold structure and does not impair its mechanical properties [37,38].

Matsuzaki et al., has also attempted to embed already-submerged heparin particles deep into the scaffold by using subcritical $\mathrm{CO}_{2}$ exposure in the inner PLCL layer of our dual-layered grafts. Furthermore, it was found that reducing the heparin burst in the early stages in vitro increased the heparin release profile (Figure 2). This has the potential to further improve graft patency by embedding to a deeper level with the addition of a subcritical $\mathrm{CO}_{2}$ exposure technique. Future implantation using scaffolds larger than $5 \mathrm{~cm}$ are needed.

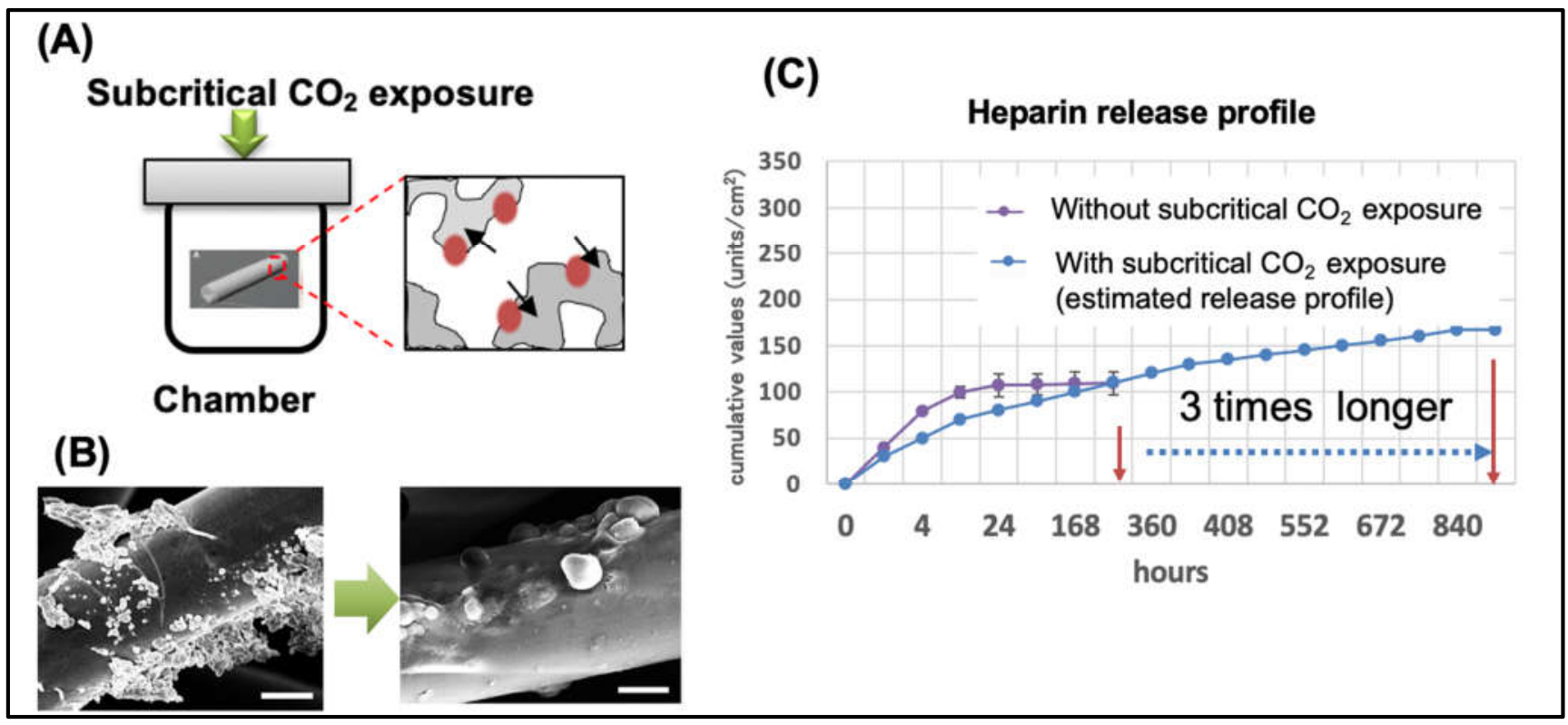

Figure 2. Subclinical $\mathrm{CO}_{2}$ technique for long-term sustained release of heparin. (A) Adaptation of subclinical $\mathrm{CO}_{2}$ exposure for TEVG. (B) Scanning electron microscopy (SEM) of HB-EGF on the scaffold. (C) Long release profile. Adopted with permission from Shinoka et al.

Antonova et al. have shown that polyhydroxybutyrate/valerate(PHBV)/polycaprolactone (PCL) grafts modified with growth factors such as VEGF, bFGF, and SDF- $1 \alpha$ (PHBV/ PCL-GFmix) performed well when implanted in the rat abdominal aortas [29]. Subsequently, they used a sheep model, which is considered to be more suitable for the in vivo testing of cardiovascular implants [39]. They had expectations of a high incidence of thrombosis in a sheep model; therefore, attempted to reduce the thrombogenicity of the PHBV/PCL-GFmix grafts by combining heparin and iloprost on the surface of the grafts. At the end of one year, 50\% of the PHBV/PCL-GFmixHep/Ilo grafts were completely patent, indicating that modification with heparin and iloprost can greatly improve the performance of PHBV/PCL grafts in the experimental large animal models [40].

\subsubsection{Coaxial Electrospinning Technique}

Electrospinning technology is often used to create grafts that take into account a variety of important properties of bioabsorbable synthetic grafts, such as degradation rate, response to high-pressure environments (arteries), and cell infiltration rate. Among 
electrospun materials, synthetic or natural polymers such as PLLA, PCL, PGA, collagen, fibrin gel, and chitosan are frequently used [41].

Coaxial electrospinning has been widely used to produce scaffolds with heparin blends. Coaxial electrospinning (Figure 3 ) is an extension of regular electrospinning. It can mix different materials in different ratios to produce core and shell fibers. The grafts made by coaxial electrospinning also can cooperate with different drugs, proteins, and cells. Furthermore, coaxial electrospinning has been shown to produce scaffolds that can mimic the natural ECM in terms of fiber alignment and scaffold seamlessness [42].

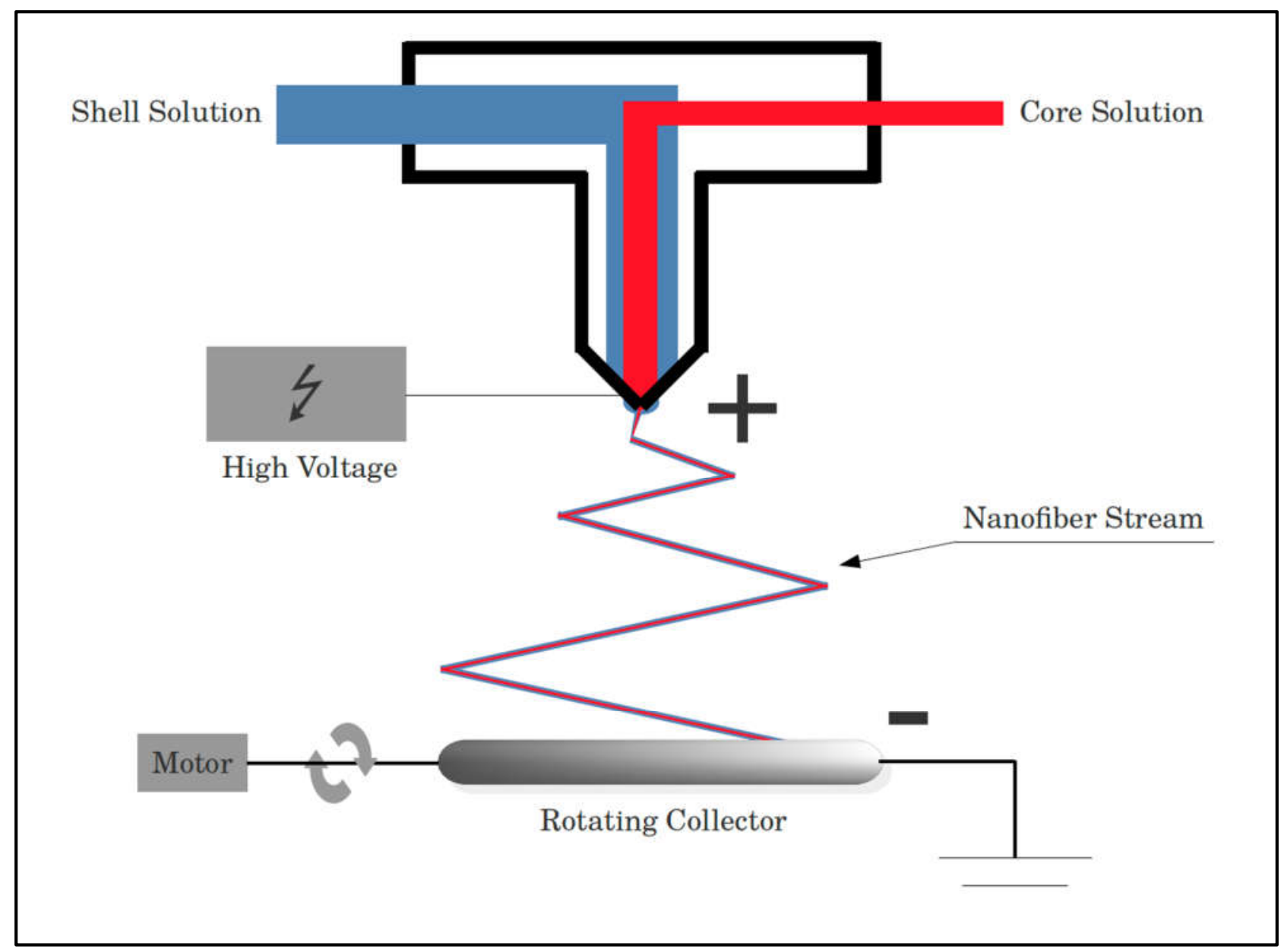

Figure 3. A scheme of coaxial electrospinning. Two separate syringes pump core (heparin) and shell solutions at different feeding rates to a rotating collector under working voltage. The needle tip to collector distance and collector rotating speeds can be adjusted.

Coaxial electrospinning conjugation technology has been shown to inhibit thrombus deposition associated with heparin-induced changes in the electrified environment of the material, and at the same time, it has been shown to regulate SMC growth by adjusting the fiber and pore diameters of the electrospun fibers while creating the graft. This is considered to be superior to other physical conjugation methods [43]. In terms of materials, PCL and PLLA are used as grafting materials because of their longer degradation period and higher mechanical strength compared to other materials. In addition, poly(l-lactide-co$\varepsilon$-caprolactone) (P(LLA-CL)) copolymers are very popular among small-diameter arterial graft blends [25]. Huang et al., compared P(LLA-CL) (50:50), endothelialized P(LLACL) and heparinized P(LLA-CL) grafts in a canine femoral artery model. This group used coaxial electrospinning with two syringes pumping $6 \%$ PLLA-CL and $12 \%$ heparin solutions, respectively [26]. 
The patency rate at day 7 for both pure P(LLA-CL) and endothelialized P(LLA-CL) groups was $75 \%$, while P(LLA-CL)/heparin was $100 \%$. For pure P(LLA-CL) on day 14 , the endothelialized P(LLA-CL) was $25 \%$ when P(LLA-CL)/Heparin was $50 \%$; the patency rate for the $\mathrm{P}(\mathrm{LLA}-\mathrm{CL}) /$ Heparin group on day 30 was $25 \%$ compared to $0 \%$ for the other groups. There was no endothelialization along the graft luminal surface in the P(LLACL)/Heparin graft. The Cheng group similarly examined heparin-loaded grafts. However, they were concerned that their combination might not be sufficient to maintain patency for a longer time period, therefore they considered a blend of natural polymers. The synergistic effects of combining P(LLA-CL) with natural polymers, vascular endothelial growth factor (VEGF), and heparin encapsulation altered the graft lumen's surface and had a marked effect on surface endothelialization [23].

Other experiments using natural polymers include one recent study on a rabbit infrarenal aortic model. They compared heparin/P(LLA-CL)/collagen/elastin, P(LLACL)/collagen/elastin with VEGF, and ePTFE before endothelialization. The grafts were prepared using P(LLA-CL) with heparin and VEGF. Heparin and VEGF had a synergistic effect with each other for slower heparin release and longer VEGF bioactivity. The results showed that the test group maintained a higher patency than the other control groups, and the graft specimens at day 7 proved that endothelialization had occurred sufficiently by using DAPI staining [26].

On the other hand, Wang's group hypothesized that a certain P(LLA-CL) blend, a blend of $60 \%$ PCL and 40\% PLLA, could simulate native ECM and found that it could mimic natural blood vessels without the addition of natural materials [26]. They conducted an in vivo study by implanting heparin pre-endothelialized P(LLA-CL) grafts into canine femoral arteries. Heparin was conjugated by coaxial electrospinning as in the other group, but they employed a higher heparin solution concentration of $25 \%$. Their heparin-bound graft was more than $85 \%$ patent compared to $37.5 \%$ patent for the control PLLA-CL after 24 weeks. They also noted that heparin binding to P(LLA-CL) decreased the maximum scaffold tensile strength and initial burst of heparin release, while increasing its elasticity and suture retention [30].

Not only is P(LLA-CL) useful, electrospun PCL also has its uses: Luong-Van et al. suggest that among the many bioabsorbable materials, PCL electrospun fibers can be used to increase the amount of release. Specifically, an $8 \% \mathrm{w} / \mathrm{v}$ solution of heparin in polycaprolactone (PCL) was spun with 7:3 dichloromethane:methanol to produce fibers with a smooth surface [44]. The sustained release of heparin was confirmed by fluorescent labeling, and after 14 days, about half of the encapsulated heparin was released from the heparin/PCL fiber by diffusion control, indicating good, sustained release. Duan et al. fabricated tubular vascular tissue engineering scaffolds with fibers in a core-shell structure using a coaxial electrospinning method with an appropriate flow ratio of inner and outer solutions. PCL was used as the core to give the scaffold mechanical properties and integrity, and collagen was used as the shell to improve vascular cell attachment and proliferation due to its excellent biocompatibility [31].

Furthermore, the functional inner layer using a coaxial electrospinning technique is expected to prevent the acute thrombosis of non-bioabsorbable materials such as ePTFE and promote rapid endothelialization of artificial vascular grafts. Based on this finding, salvianolic acid B (SAB) promotes the proliferation and migration of endothelial cells. Kuang et al., fabricated the inner layer of an artificial graft using coaxial electrospinning and loaded it with heparin and SAB [45]. Kim et al. reported that in situ implantation of ePTFE grafts coated with heparin/substance P-conjugated PLCL could ensure longterm patency by forming a proper endothelial layer and smooth muscle cells in the graft, resembling a native artery [46].

Based on the above, physical heparin conjugation can change a graft lumen's surface charge and solve the problem of early thrombosis. However, there are few reports on their effect in long-term animal studies. 
Physically conjugated heparin grafts may be pretreated first or blended with natural polymers to promote EC adhesion and proliferation. Furthermore, bioabsorbable materials with heparin could be used to increase the biocompatibility of existing nonbioabsorbable materials. Future reports in long-term large animal studies on the efficacy of grafts physically conjugated with heparin are awaited.

\subsection{Chemical Conjugation}

This section describes how to chemically conjugate heparin to bioabsorbable materials. Ionic and covalent bonding reactions are the main methods used for chemical conjugation. Chemical immobilization of heparin on an ionized surface provides long-term stability of the drug. This has also been reported to be a very efficient and affordable approach However, it has also been suggested that this method may be complicated due to multi-step coating and repeated cleaning and drying of the inner luminal membrane.

\subsubsection{Covalent Interaction}

Heparin which is covalently bonded to surfaces has been proven to last longer than electrostatically bonded heparin. Covalent bonding of heparin is the best option to solve the problem of burst release. Additionally, this approach promotes resistance to mechanical forces at the blood and luminal surface interface [45].

However, the carboxyl groups present on heparin molecules contribute to the drug's mobilization, which limits binding to proteins and may reduce its anticoagulant properties. The lack of heparin bioactivity may be due to ineffective immobilization methods. Heparin conjugated with covalent or ionic bonds is not easily removed by water rinsing, but it has also been suggested that heparin may be depleted over time in the presence of blood flow, exposing a surface without anticoagulant [47].

Chemical conjugation of heparin can be achieved using covalent cross-linkers between the carboxyl groups in the heparin molecule, and amino covalent heparin immobilization to scaffolds is often intended to mediate the addition of growth factors via electrostatic interactions between heparin and the added protein (growth factor such as VEGF) (Figure 4).

With the addition of growth factors, heparin not only exhibits a sustained release profile (details in the next section), but also the highest activated partial thromboplastin time (APTT) to date, with a reported synergistic effect of sustained growth factor release rate and no burst release for up to three weeks. As mentioned in the previous section, the negative charge of heparin may inhibit the fibrinogen adsorption [24].

Ye et al., hypothesized that increasing the hydrophilicity of heparinized electrospun PCL scaffolds and negative charge of heparin may inhibit the fibrinogen adsorption [27]. In vivo studies in a canine model have shown that their heparin-containing scaffold remains patent after one month, and a nearly confluent layer of ECs was observed in the graft lumen. The high cytocompatibility of the scaffolds may be attributed to heparin molecules, possibly promoting cell adhesion and proliferation by entrapping VEGF in the blood. As also mentioned in physical conjugation, it is possible to exploit the flexibility and structural integrity of PLLA and PLCL polymers to fabricate heparinized nanofibers [34]. Recently, the Wang group prepared various P(LLA-CL) blends using the TIPS method, and then conjugated them with heparin using carbodiimide chemistry/EDC/NHS, which utilizes the esterification reaction between the terminal hydroxyl groups of PLLA and PLCL and the carboxyl groups of heparin molecules (Figure 3) [48]. 


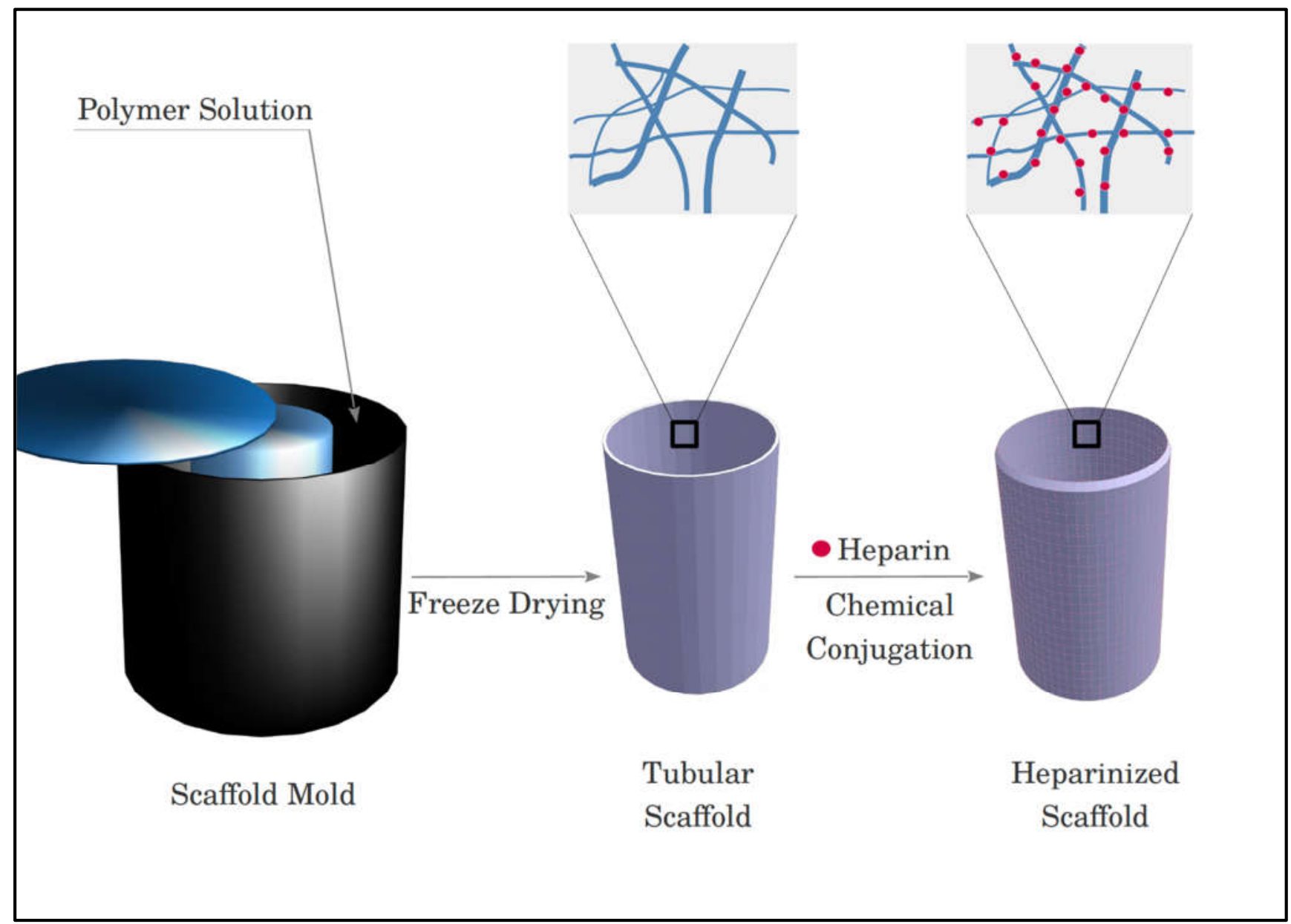

Figure 4. A scheme of chemical conjugation. Mixture of solution was poured to heated molding chamber and freeze-dried at $-80{ }^{\circ} \mathrm{C}$. Lastly, heparin added to the scaffold for covalent bonding.

In another study, VEGF was covalently bonded to hydrophilic heparin molecules. The VEGF-heparin molecules were then coaxially electrospun with P(LLA-CL) as the shell, and then combined to a collagen-elastin core material [31]. Heparin had an initial burst release causing a cumulative release of $48 \%$ on day one, although it continued to be released for 22 days; they concluded that the burst release of VEGF and structures in collagen may be the reason for the rapid growth of seeded endothelial cells. There is also an innovative method that uses photopolymerization reactions, which are part of covalent bonding.

Heparin-functionalized bioabsorbable microspheres and nanoparticles have been widely reported for the delivery of several growth factors such as basic fibroblast factor (bFGF) and vascular endothelial growth factor (VEGF) [49-51]; in these nanostructures, the development of nanosponge technology is remarkable. Nanosponges refer to a class of nanomaterials with nanoporous structures and excellent absorption/composite properties. Various "nanosponges" based on organic/polymeric and inorganic materials been reported [52-56]. These have high volume expansions in addition to being porous [57]. Choi et al., searched for a chemically stable vehicle for the sustained release of various growth factors. They developed a method to form photo-crosslinked, thermosensitive heparin nanosponges (Hep-NS) by a one-step photopolymerization reaction of diacylated and thiolated heparin molecules [58]. In vitro studies showed that their Hep-NS sustained the release of all growth factors for almost 60 days, which was similar and directly correlated to the amount of heparin released. These heparin nanosponges are good candidates for a long-term sustained release system until scaffolds are fully endothelialized. 


\subsubsection{Electrostatic Interactions}

Heparin-loaded gelatin electrospun scaffolds have been used to exploit the drug delivery potential of heparin scaffolds as vascular grafts [32]. Heparin-containing scaffolds were developed by exploiting the electrostatic interaction between positively charged gelatin and negatively charged heparin. Sustained release of heparin was observed from the gelatin-heparin scaffold in vitro over a period of 14 days. Biocompatibility studies performed with human umbilical vein endothelial cells (HUVECs) in vitro showed that cell viability and proliferation were better on the gelatin-heparin scaffold when compared to the control. In a study by Choi et al., electrospun grafts were prepared from polyurethane elastomer (PU) containing cell adhesion peptides and heparin as an anticoagulant [58]. The cell adhesion peptides enhance effective EC adhesion, which is essential for the biocompatibility of the scaffold. The bio-functionalization of the scaffold was confirmed in vitro by increased HUVEC adhesion and cell proliferation. A significant increase in patency of the surface-modified graft compared to the pristine polyurethane graft was also reported in a 60-day validation. The patency rate at nine weeks after grafting was significantly higher in the modified PU graft (71.4\%) than in the control graft $(46.2 \%)$. The non-treated PU grafts showed higher levels of $\alpha$-SMA expression compared to the modified grafts.

Additionally, heparin conjugation is useful to prevent the thrombosis of otherwise positively charged materials due to its highly negative charge. As such, some groups have improved sustained heparin release by changing the surface charge. Zhu's group selected mesoporous silica SBA-15 composed of silicon for the sustained release of heparin and optimized the surface conditions of their bioengineered scaffold. Their modified SBA-15 material promoted the sustained release of heparin and extended the release equilibrium time up to 60 days. Furthermore, the APTES-modified SBA-15 sample was able to capture three-fold more heparin than the parent SBA-15 due to the positive charge that attracted heparin through electrostatic interaction, increasing the release rate to $80 \%$ (38\% for SBA15) $[59,60]$. These results suggest the feasibility of this approach.

\section{Discussion}

This review describes two methods to improve small-diameter arterial graft patency. One, the heparin conjugation method, improves the patency of grafts made from bioabsorbable materials. The second is a method of extending the suspended release period of heparin to maintain the graft patency rate for a longer time. Adequate and sustained heparin release is considered a means of increasing graft patency, while the long-term endothelialization process is completed. Heparin has been shown to prevent thrombosis associated with thrombin suppression, inhibition of vascular smooth muscle cell (VSMC) proliferation, and prevention of graft occlusion [61,62], but that is not all. Heparin can also stabilize physiologically unstable growth factors in the heparin-binding domain $[63,64]$. Heparin has the potential to overcome the challenges associated with growth factor instability in solution, self-aggregation, low bioavailability, short half-life in vivo, and in vivo delivery [65-67]. This has led to many advances in the patency of the smallest diameter tissue-engineered arterial grafts.

In addition, to test the efficiency of TEVG grafting in these studies, small animal models are not suitable for preclinical testing due to the differences in metabolism and arterial pressure from humans. It is necessary to test the efficacy and safety of these materials in large animal models such as sheep or pigs prior to clinical trials. In fact, in this review, we have focused on experiments performed on large animal models.

Although we have no choice but to use animals, we must always consider the three Rs of animal use (reduction, refinement, and replacement) in order to protect the animals. For instance, adequate mechanical strength should be verified before implantation in the animals.

Before implanting the grafts to the animals, some in vitro tests need to be performed. For example, the tensile strength test alone is not sufficient to ensure that the graft will not cause an aneurysm in an arterial environment. Thus, beating tests simulating arterial 
pressure [68], and evaluation of heparin release using the toluidine blue method must be performed $[27,28]$. In vitro evaluations of biocompatibility, such as platelet deposition on the luminal surface of the graft and the LDH assay [26], are necessary. For the biodegradability, although different reagents are used for different polymers, we should verify the degradation rates of different biodegradable grafts using serial accelerated degradation studies [69].

Due to the nature of tissue engineering grafts, some studies expect neo-tissue formation using materials with fast degradation rates [70,71]. In the arterial environment, these grafts tend to dilate relatively quickly. Hence, materials with a longer degradation period are preferable at this point. Animal studies should be performed with grafts that meet the above in vitro criteria.

Many studies have shown that endothelialization is important to maintain graft patency. However, these studies shown transanal endothelial growth at most of 1 to $2 \mathrm{~cm}$ [44]. This might be the reason why TEVG has been relatively successful in experimental models such as sheep carotid or porcine femoral arteries, where $2-5 \mathrm{~cm}$ prostheses have been evaluated (currently, the recommended length of TEVG is limited to 10 times the diameter (4-6 cm for ovine carotid grafts), but clinically, coronary and lower limb bypass graft prostheses are, on average, $15 \mathrm{~cm}$ in length [72].

Hematogenous or percutaneous endothelialization is a time-consuming process, and large-animal experimental designs need to use grafts $>5 \mathrm{~cm}$ in length to validate clinical importance. After grafting, if patency can be maintained without graft dilatation, longterm observation for about one year is desirable. In regenerative medicine research, the assessment of tissue regeneration and inflammation typically requires animal sacrifice and graft harvesting for histological evaluation. There are existing imaging methods, such as echocardiography and angiography, that can assess the in vivo characteristics of implanted arterial grafts. However, these methods are generally limited to anatomical evaluations of luminal diameter, neo-tissue formation, and flow velocity. Imaging tools that can evaluate tissue regeneration in vivo, while the animal is alive, will be helpful in the future. We are currently examining the use of nuclear medicine to evaluate the neo-tissue formation in grafts [73]. It would be ideal if we could prove safety by sacrificing the fewest number of large animals possible, use computational modeling to simulate optimal graft design and heparin release, and design a clinical trial.

In conclusion, although there are many obstacles to overcome, advances in heparinbinding technology have further improved the patency of these experimental grafts. The impact of this research on the field of clinical cardiovascular surgery will be tremendous.

Author Contributions: The authors confirm contributions to the paper as follows: Y.M., A.U., T.S. (Toshihiro Shoji) and T.S. (Toshiharu Shinoka) assisted with conception and design. Y.M. and A.U. assisted with drafting of the manuscript. Y.M., T.S. (Toshihiro Shoji) and T.S. (Toshiharu Shinoka) contributed to critical revision of the manuscript. All authors have read and agreed to the published version of the manuscript.

Funding: This research received no external funding.

Institutional Review Board Statement: The study was conducted according to the guidelines of the Declaration of Helsinki, and The Institutional Animal Care and Use Committee of Nationwide Children's Hospital (Columbus, OH, U.S.) reviewed and approved the protocol for the ovine study (AR19-00104).

Informed Consent Statement: Not applicable.

Data Availability Statement: Data supporting reported results of this study can be found in publicly archived datasets as specified in links throughout the manuscript.

Acknowledgments: This research is supported by GUNZE Co ltd. YM was supported by the Department of Defense (DoD) and the Funding award from the Uehara Memorial Foundation (Tokyo Japan) in 2019. The specific roles of these authors are articulated in the 'Author Contributions' section.

Conflicts of Interest: The authors declare no conflict of interest. 
Disclosure: The authors have read the journal's policy and the authors of the manuscript have the following competing interests: TS has received grant support from Gunze Ltd. No authors have received salary support from Gunze Ltd. This does not alter our adherence to Applied Sciences policies on sharing data and materials. There are no patents, products in development, or marketed products to declare.

$\begin{array}{ll}\text { Abbreviations } \\ \text { APTT } & \text { Activated Partial Thromboplastin Time } \\ \text { b-FGF } & \text { basic Fibroblast Growth Factor, } \\ \text { DAPI } & \text { 4',6-diamidino-2-phenylindole } \\ \text { EC } & \text { Endothelial Cell } \\ \text { ECM } & \text { Extracellular Matrix } \\ \text { FDA } & \text { Food and Drug Administration } \\ \text { Hep-NS } & \text { Heparin Nanosponges } \\ \text { HBF-GF } & \text { Heparin-binding EGF-like growth factor } \\ \text { HUVECs } & \text { Human Umbilical Vein Endothelial Cells } \\ \text { PAD } & \text { Peripheral Artery Disease } \\ \text { PLCL } & \text { Polylactide-co-epsilon-caprolactone } \\ \text { PCL } & \text { Polycaprolactone } \\ \text { PGA } & \text { Polyglycolic acid } \\ \text { PLLA } & \text { Poly-L-lactide acid } \\ \text { PU } & \text { Polyurethane elastomer } \\ \text { TIPS } & \text { Thermally Induced Phase Separation } \\ \text { TEVG } & \text { Tissue Engineered Vascular Graft } \\ \text { SEM } & \text { Scanning Electron Microscopy } \\ \text { SMC } & \text { Smooth Muscle Cell } \\ \text { VEGF } & \text { Vascular Endothelial Growth Factor } \\ \text { VSMC } & \text { Vascular Smooth Muscle Cell } \\ \text { XPS } & \text { X-ray Photoelectron Spectroscopy }\end{array}$

\section{References}

1. Ercolani, E.; Del Gaudio, C.; Bianco, A. Vascular tissue engineering of small-diameter blood vessels: Reviewing the electrospinning approach. J. Tissue Eng. Regen. Med. 2015, 9, 861-888. [CrossRef] [PubMed]

2. Wang, H.; Feng, Y.; Fang, Z.; Xiao Yuan, W.; Khan, M. Fabrication and characterization of electrospun gelatin-heparin nanofibers as vascular tissue engineering. Macromol. Res. 2013, 21, 860-869. [CrossRef]

3. Mulloy, B.; Hogwood, J.; Gray, E.; Lever, R.; Page, C.P. Pharmacology of heparin and related drugs. Pharmacol. Rev. 2016, 68, 76-141. [CrossRef] [PubMed]

4. Zia, F.; Zia, K.M.; Zuber, M.; Tabasum, S.; Rehman, S. Heparin based poly- urethanes: A state-of-the-art review. Int. J. Biol. Macromol. 2016, 84, 101-111. [CrossRef]

5. Nie, T.; Baldwin, A.; Yamaguchi, N.; Kiick, K.L. Production of heparin-functionalized hydrogels for the development of responsive and controlled growth factor de- livery systems. J. Control. Release 2007, 122, 287-296. [CrossRef]

6. Zong, Z.; Kim, K.; Fang, D.; Ran, S.; Hsiao, B.; Chu, B. Structure and process relationship of electrospun bioabsorbable nanofiber membranes. Polymers 2002, 43, 4403-4412. [CrossRef]

7. Thomas, D.; O'Brien, T.; Pandit, A. Toward Customized Extracellular Niche Engineering: Progress in Cell-Entrapment Technologies. Adv. Mater. 2018, 30. [CrossRef]

8. Nicolas, J.; Magli, S.; Rabbachin, L.; Sampaolesi, S.; Nicotra, F.; Russo, L. 3D Extracellular Matrix Mimics: Fundamental Concepts and Role of Materilas Chemistry to Influence Stem Cell Fate. Biomacromolecules 2020, 21, 1968-1994. [CrossRef]

9. Matsuzaki, Y.; Iwaki, R.; Reinhardt, J.W.; Chang, Y.C.; Miyamoto, S.; Kelly, J.; Zbiden, J.; Blum, K.; Mirhaidari, G.; Ulzibayar, A.; et al. The effect of pore diameter on neo-tissue formation in electrospun biodegradable tissue-engineered arterial grafts in a large animal model. Acta Biomater. 2020, 115, 176-184. [CrossRef] [PubMed]

10. Yoss, H.S.; Kim, T.G.; Park, T.G. Surface-functionalized electrospun nanofibers for tissue engineering and drug delivery. Adv. Drug Deliv. Rev. 2009, 61, 1033-1042.

11. Hchmedien, R.H.; ELbjeirami, W.M.; Gobin, A.S.; West, J.L. Tissue engineered small-diameter vascular grafts. Clin. Plast. Surg. 2003, 30, 507-517.

12. Tara, S.; Rocco, K.A.; Hibino, N.; Sugiura, T.; Kurobe, H.; Breuer, C.K.; Shinoka, T. Vessel bioengineering. Circ. J. 2014, 78, 12-19. [CrossRef] [PubMed] 
13. Escudero, M.C.; Alvarez, L.; Haro, J.; Millan, I.; Jorge, E.; Castillo-Olivares, J.L. Prevention of thrombus formation on biomaterials exposed to blood using different antiplatelet drugs: Experimental study in dogs. J. Biomed. Mater. Res. 1994, 28, 1-6. [CrossRef] [PubMed]

14. Bertholf, R.L. Proteins and Albumin. Lab. Med. 2014, 45, 25-41. [CrossRef]

15. Grover, S.P.; Mackman, N. Intrinsic Pathway of Coagulation and Thrombosis Insights From Animal Models. Arterioscler. Thromb. Vasc. Biol. 2019, 39, 331-338. [CrossRef] [PubMed]

16. Ye, L.; Wu, X.; Mu, Q.; Chen, B.; Duan, Y.; Geng, X. Heparin-conjugated PCL scaffolds fabricated by electrospinning and loaded with fibroblast growth factor 2. J. Biomater. Sci. Polym. 2011, 22, 389-406. [CrossRef]

17. Seifu, D.G.; Purnama, A.; Mequanint, K.; Mantovani, D. Small-diameter vascular tissue engineering. Nat. Rev. Cardiol. 2013, 10, 410-421. [CrossRef]

18. Zhou, M.; Liu, Z.; Wei, Z.; Liu, C.; Qiao, T.; Ran, F. Development and vali- dation of small-diameter vascular tissue from a decellularized scaffold coated with heparin and vascular endothelial growth factor. Artif. Organs 2009, 33, 230-239. [CrossRef]

19. Liu, T.; Zeng, Z.; Liu, Y.; Wang, J.; Maitz, M.F.; Wang, Y. Surface modification with dopamine and heparin/poly-L-lysine nanoparticles provides a favorable release behavior for the healing of vascular stent lesions. ACS Appl. Mater. Interfaces 2014, 6, 8729-8743. [CrossRef]

20. Roberts, J.J.; Farrugia, B.L.; Green, R.A.; Rnjak-Kovacina, J.; Martens, P.J. In situ formation of poly (vinyl alcohol)-heparin hydrogels for mild encapsulation and prolonged release of basic fibroblast growth factor and vascular endothelial growth factor. J. Tissue Eng. 2016, 7. [CrossRef]

21. Liang, Y.; Kiick, K.L. Heparin-functionalized polymeric biomaterials in tissue engineering and drug delivery applications. Acta Biomater. 2014, 10, 1588-1600. [CrossRef] [PubMed]

22. Aslani, S.; Kabiri, M.; HosseinZadeh, S.; Hanaee-Ahvaz, H.; Taherzadeh, E.S.; Soleimani, M. The applications of heparin in vascular tissue engineering. Microvasc. Res. 2020, 131, 104027. [CrossRef] [PubMed]

23. Cheng, C.; Sun, S.; Zhao, C. Progress in heparin and heparin-like/mimicking polymer-functionalized biomedical membranes. J. Mater. Chem. B 2014, 2, 7649-7672. [CrossRef] [PubMed]

24. Wan, Y.; Gao, C.; Han, M.; Liang, H.; Ren, K.; Wang, Y. Preparation and characterization of bacterial cellulose/heparin hybrid nanofiber for potential vascular tissue engineering scaffolds. Polym. Adv. Technol. 2011, 22, 2643-2648. [CrossRef]

25. Del Gaudio, C.; Baiguera, B.; Boieri, M.; Mazzanti, B.; Ribatti, D.; Bianco, A.; Macchiarini, P. Induction of angiogenesis using vegf releasing genipin crosslinked electrospun gelatin mats. Biomaterials 2013, 34, 7754-7765. [CrossRef] [PubMed]

26. Huang, C.; Wang, S.; Qiu, L.; Ke, Q.; Zhai, W.; Mo, X. Heparin loading and preendothelialization in enhancing the patency rate of electrospun small-diameter vascular grafts in a canine model. ACS Appl. Mater. Interfaces 2013, 5, 2220-2226. [CrossRef] [PubMed]

27. Hu, S.; Zhang, P.; Sun, X.; Gong, F.; Yang, S.; Shen, L. Synthetic e-PTFE grafts coated with an anti-CD133 antibody-functionalized heparin/collagen multilayer with rapid in vivo endothelialization properties. ACS Appl. Mater. Interfaces 2013, 5, 7360-7369.

28. Matsuzaki, Y.; Miyamoto, S.; Miyachi, H.; Iwaki, R.; Shoji, T.; Blum, K.; Chang, Y.C.; Kelly, J.; Reinhaldt, J.W.; Nakayama, H.; et al. Improvement of Novel Small-Diameter Tissue Engineered Arterial Graft with Heparin Conjugation. Ann. Thorac. Surg. 2020, 16, 1234-1241. [CrossRef]

29. Antonova, L.V.; Mironov, A.V.; Yuzhalin, A.E.; Krivkina, E.O.; Shabaev, A.R.; Rezvova, M.A.; Tkachenko, V.O.; Khanova, M.Y.; Sergeeva, T.Y.; Krutitskiy, S.S.; et al. A Brief Report on an Implantation of Small-Caliber Biodegradable Vascular Grafts in a Carotid Artery of the Sheep. Pharmaceuticals 2020, 13, 101. [CrossRef]

30. Wang, W.; Hu, J.; He, C.; Nie, W.; Feng, W.; Qiu, K. Heparinized PLLA/PLCL nanofibrous scaffold for potential engineering of small-diameter blood vessel: Tunable elasticity and anticoagulation property. J. Biomed. Mater. Res. A 2015, 103, 1784-1797. [CrossRef]

31. Duan, N.; Geng, X.; Ye, L.; Zhang, A.; Feng, Z.; Guo, L. A vascular tissue engineering scaffold with core-shell structured nano-fiberformed by coaxial electrospinning and its biocompatibility evaluation. Biomed. Mater. 2016, 11, 035007. [CrossRef]

32. Hoshi, R.A.; Van Lith, R.; Jen, M.C.; Allen, J.B.; Lapidos, K.A.; Ameer, G. The blood and vascular cell compatibility of heparinmodified ePTFE vascular grafts. Biomaterials 2013, 34, 30-41. [CrossRef]

33. Smith, P.K.; Krohn, R.I.; Hermanson, G.T. Colorimetric method for the assay of heparin content in immobilized heparin preparation. Anal. Biochem. 1980, 109, 466-473. [CrossRef]

34. D'ilario, L.; Francolini, I.; Martinelli, A.; Piozzi, A. Insight into the Heparin-Toluidine Blue (C.I.Basic Blue17) interaction. Dye. Pigment. 2009, 80, 343-348. [CrossRef]

35. Jungebluth, P.; Bader, A.; Baiguera, S.; Moller, S.; Jaus, M.; Lim, M.L.; Fried, K.; Kjartansdottir, K.R.; Go, T.; Nave, H.; et al. The concept of in vivo airway tissue engineering. Biomaterials 2012, 33, 4319-4326. [CrossRef] [PubMed]

36. Liu, Y.; Nelson, T.; Cromeens, B.; Rager, T.; Lannutti, J.; Johnson, J.; Benser, G.E. HB-EGE embedded in PGA/PLLA scaffolds via subcrinical $\mathrm{CO}_{2}$ augments the production of tissue engineered intestine. Biomaterials 2016, 103, 150-159. [CrossRef] [PubMed]

37. Powell, H.M.; Ayodeji, O.; Summerfield, T.L.; Powell, D.M.; Kniss, D.A.; Tomasko, D.L. Chemotherapeutic implants via subcritical CO2 modification. Biomaterials 2007, 28, 5562-5569. [CrossRef] [PubMed]

38. Dormer, N.H.; Gupta, V.; Scurto, A.M.; Berkland, C.J.; Detamore, M.S. Effect of different sintering methods on bioactivity and releaseof proteins from PLGA microspheres. Mater. Sci. Eng. C Mater. Biol. Appl. 2013, 33, 4343-4351. [CrossRef] [PubMed] 
39. Antonova, L.V.; Sevostyanova, V.V.; Kutikhin, A.G.; Velikanova, E.A.; Matveeva, V.G.; Glushkova, T.V.; Mironov, A.V.; Krivkina, A.V.; Barbarash, O.L.; Barbarash, L.S. Influence Of bFGF, SDF-1 $\alpha$, or VEGF incorporated into tubular polymer scaffolds on the formation of small-diameter tissue-engineered blood vessel in vivo. Vestn. Transpl. Iskusstv. Organov. 2018, 20, 96-109. [CrossRef]

40. Yun, Y.R.; Won, J.E.; Jeon, E.; Lee, S.; Kang, W.; Jo, H.; Jang, J.H.; Shin, U.S.; Kim, H.W. Fibroblast growth factors: Biology, function, and application for tissue regeneration. J. Tissue Eng. 2010, 1, 218142. [CrossRef]

41. Matsuzaki, Y.; Kelly, J.; Shoji, T.; Shinoka, T. The evolution of tissue engineered vascular graft technologies: From preclinical trials to advancing patient care. Appl. Sci. 2019, 9, 1274. [CrossRef]

42. Rocco, K.A.; Maxfield, M.W.; Best, C.A.; Dean, E.W.; Breuer, C.K. In vivo applications of electrospun tissue-engineered vascular grafts: A review. Tissue Eng. Part B Rev. 2014, 20, 628-640. [CrossRef]

43. Wang, S.; Mo, X.M.; Jiang, B.J.; Gao, C.J.; Wang, H.S.; Zhuang, Y.G.; Qiu, L.J. Fabrication of small-diameter vascular scaffolds by heparin-bonded P(LLA-CL) composite nanofibers to improve graft patency. Int. J. Nanomed. 2013, 8, 2131-2139. [CrossRef] [PubMed]

44. Luong-van, E.; Grondahl, L.; Chua, K.N.; Leong, K.W.; Nurcombe, V.; Cool, S.M. Controlled release of heparin from poly( $\varepsilon-$ caprolactone) electrospun fibers. Biomaterials 2006, 27, 2042-2050. [CrossRef] [PubMed]

45. Liu, T.; Liu, Y.; Chen, Y.; Liu, S.; Maitz, M.F.; Wang, X. Immobilization of heparin/poly-l-lysine nanoparticles on dopamine-coated surface to create a heparin density gradient for selective direction of platelet and vascular cells behavior. Acta Biomater. 2014, 10, 1940-1954. [CrossRef]

46. Ye, L.; Wu, X.; Duan, H.Y.; Geng, X.; Chen, B.; Gu, Y.Q. The in vitro and in vivo biocompatibility evaluation of heparin-poly ( $\varepsilon$-caprolactone) conjugate for vascular tissue engineering scaffolds. J. Biomed. Mater. Res. 2012, 100, 3251-3258. [CrossRef] [PubMed]

47. Hu, Y.T.; Pan, X.D.; Zheng, J.; Ma, W.G.; Sun, L.Z. In vitro and in vivo evaluation of a small-caliber coaxial electrospun vascular graft loaded with heparin and VEGF. Int. J. Surg. 2017, 44, 244-249. [CrossRef]

48. Jeon, O.; Kang, S.W.; Lim, H.W.; Chung, J.H.; Kim, B.S. Long-term and zero-order release of basic fibroblast growth factor from heparin-conjugated poly(L-lactide-co-glycolide) nanospheres and fibrin gel. Biomaterials 2006, 27, 1598-1607. [CrossRef]

49. Chung, H.J.; Kim, H.K.; Yoon, J.J.; Park, T.G. Heparin immobilized porous PLGA microspheres for angiogenic growth factor delivery. Pharm. Res. 2006, 23, 1835-1841. [CrossRef]

50. Chung, Y.I.; Tae, G.; Yuk, S.H. A facile method to prepare heparin-functionalized nanoparticles for controlled release of growth factors. Biomaterials 2006, 27, 2621-2626. [CrossRef]

51. Jeon, O.; Powell, C.; Solorio, L.D.; Krebs, M.D.; Alsberg, E. Affinity-based growth factor delivery using biodegradable, photocrosslinked heparin-alginate hydrogels. J. Control. Release 2011, 154, 258-266. [CrossRef]

52. Choi, J.H.; Joung, Y.K.; Bae, J.W.; Choi, J.W.; Quyen, T.N.; Park, K.D. Self-assembled nanogel of Pluronic-conjugated heparin as a versatile drug nanocarriers. Macromol. Res. 2011, 19, 180-188. [CrossRef]

53. Cavalli, R.; Akhter, A.K.; Bisazza, A.; Giustetto, P.; Trotta, F.; Vavia, P. Nanosponge formulations as oxygen delivery systems. Int J. Pharm. 2010, 402, 254-257. [CrossRef] [PubMed]

54. Hariri, G. Sequential targeted delivery of paclitaxel and camptothecin using a cross-linked "nanosponge" network for lung cancer chemotherapy. Mol. Pharm. 2014, 11, 265-275. [CrossRef] [PubMed]

55. Zheng, T.; Li, G.G.; Zhou, F.; Wu, R.; Zhu, J.J.; Wang, H. Gold-nanosponge-based multistimuli-responsive drug vehicles for targeted chemo-photothermal therapy. Adv. Mater. 2016, 28, 8218-8226. [CrossRef]

56. Ataee-Esfahani, H.; Nemoto, Y.; Wang, L.; Yamauchi, Y. Rational synthesis of Pt spheres with hollow interior and nanosponge shell using silica particles as template. Chem. Commun. 2011, 47, 3885-3887. [CrossRef]

57. Choi, W.; Sahu, A.; Vilos, C.; Kamaly, N.; Jo, S.M.; Lee, J.H.; Tae, G. Bioinspired Heparin Nanosponge Prepared by Photocrosslinking for Controlled Release of Growth Factors. Nat. Breifing Sci. Rep. 2017, 7, 14351. [CrossRef]

58. Choi, W.S.; Joung, Y.S.; Lee, Y.; Bae, J.W.; Park, H.K.; Park, Y.H.; Park, J.C.; Park, K.D. Enhanced Patency and Endothelialization of Small-Caliber Vascular Grafts Fabricated by Coimmobilization of Heparin and Cell-Adhesive Peptides. ACS Appl. Mater. Interfaces 2016, 8, 4336-4346. [CrossRef]

59. Qian, W.J.; Wan, M.M.; Lin, W.G.; Zhu, J.H. Fabricating a sustained release of heparin using SBA-15 mesoporous silica. J. Mater. Chem. B 2014, 2, 92-101. [CrossRef]

60. Wan, M.M.; Yang, J.Y.; Qiu, Y.; Zhou, Y.; Guan, C.X.; Hou, Q.; Lin, W.G.; Zhu, J.H. Sustained release of heparin on enlarged pore and functionalized MCM41. ACS Appl. Mater. Interfaces 2012, 4, 4113-4122. [CrossRef]

61. Zilla, P.; Bezuidenhout, D.; Human, P. Prosthetic vascular grafts: Wrong models, wrong questions and no healing. Biomaterials 2007, 28, 5009-5027. [CrossRef]

62. Clowes, A.W.; Karnowsky, M.J. Suppression by heparin of smooth-muscle cell-proliferation in injured arteries. Nature 1977, 265, 625-626. [CrossRef] [PubMed]

63. Hoover, R.L.; Rosenberg, R.; Haering, W.; Karnovsky, M.J. Inhibition of rat arterial smooth muscle cell proliferation by heparin. II. In vitro studies. Circ. Res. 1980, 47, 578-583. [CrossRef] [PubMed]

64. Zhang, S.; Uludağ, H. Nanoparticulate systems for growth factor delivery. Pharm. Res. 2009, 26, 1561-1580. [CrossRef] [PubMed]

65. Tayalia, P.; Mooney, D.J. Controlled growth factor delivery for tissue engineering. Adv. Mater. 2009, 21, 3269-3285. [CrossRef] [PubMed] 
66. Richardson, T.P.; Peters, M.C.; Ennett, A.B.; Mooney, D.J. Polymeric system for dual growth factor delivery. Nat. Biotech. 2001, 19, 1029-1034. [CrossRef]

67. Anitua, E.; Sánchez, M.; Orive, G.; Andia, I. Delivering growth factors for therapeutics. Trends Pharmacol. Sci. 2008, 29 , 37-41. [CrossRef] [PubMed]

68. Matsuzaki, Y.; Wiet, M.G.; Boe, B.A.; Shinoka, T. The Real Need for Regenerative Medicine in the Future of Congenital Heart Disease Treatment. Biomedicines 2021, 9, 478. [CrossRef]

69. Agarwal, R.; Blum, K.; Musgrave, A.; Onwuka, E.A.; Reinhardt, J.W.; Best, C.; Breuer, C.K. Degradation and evaluation of polycaprolactone, poly( $\varepsilon$-caprolactone-co-L-lactide), and poly-L-lactic acid as scaffold sealant polymers for murine tissueengineered vascular grafts. Regen. Med. 2019, 14, 627-637. [CrossRef]

70. Stowell, C.E.T.; Li, X.; Matsunaga, M.H.; Cockreham, C.B.; Kelly, K.M.; Cheetham, J.; Tzeng, E.; Wang, Y. Resorbable vascular grafts show rapid cellularization and degradation in the ovine carotid. J. Tissue Eng. Regen. Med. 2020, 14, 1673-1684. [CrossRef]

71. Ran, X.; Ye, Z.; Fu, M.; Wang, Q.; Wu, H.; Lin, S.; Yin, T.; Hu, T.; Wang, G. Design, Preparation, and Performance of a Novel Bilayer Tissue-Engineered Small-Diameter Vascular Graft. Macromol. Biosci. 2019, 19, e1800189. [CrossRef] [PubMed]

72. Levine, G.N.; Bates, E.R.; Bittl, J.A.; Brindis, R.G.; Fihn, S.D.; Fleisher, L.A.; Granger, C.B.; Lange, R.A.; Mack, M.J.; Smith, S.C.; et al. 2016 ACC/AHA Guideline Focused Update on Duration of Dual Antiplatelet Therapy in Patients With Coronary Artery Disease: A Report of the American College of Cardiology/American Heart Association Task Force on Clinical Practice Guidelines: An Update of the 2011 ACCF/AHA/SCAI Guideline for Percutaneous Coronary Intervention, 2011 ACCF/AHA Guideline for Coronary Artery Bypass Graft Surgery, 2012 ACC/AHA/ACP/AATS/PCNA/SCAI/STS Guideline for the Diagnosis and Management of Patients With Stable Ischemic Heart Disease, 2013 ACCF/AHA Guideline for the Management of ST-Elevation Myocardial Infarction, 2014 AHA/ACC Guideline for the Management of Patients With Non-ST-Elevation Acute Coronary Syndromes, and 2014 ACC/AHA Guideline on Perioperative Cardiovascular Evaluation and Management of Patients Undergoing Noncardiac Surgery. Circulation 2016, 13410, e123-e155.

73. Rosamaria, T.; Chou, T.H.; Eisert, S.N.; Reinhardt, J.; Shah, K.; Matsuzaki, Y.; Zakko, J.; Shinoka, T.; Breuer, C.K.; Stacy, M.R. Non-Invasive Molecular Imaging of Inflammation In Tissue-Engineered Vascular Grafts Using 18f-Fdg Pet/Ct. J. Am. Coll. Cardiol. 2019, 75, 1768. 